\title{
НЕКОТОРЫЕ АСПЕКТЫ РАЗРАБОТКИ ИНФОРМАЦИОННОЙ СИСТЕМЫ ПОДДЕРЖКИ ПРИНЯТИЯ РЕШЕНИЙ ВРАЧА ОБЩЕЙ ПРАКТИКИ
}

\author{
Е. В. Высоцкая
}

Харьковский национальный университет радиоэлектроники

У роботі розглянуті деякі аспекти розробки інформаційної системи підтримки прийняття рішень лікаря загальної практики. Застосування запропонованого підходу дозволить лікарю загальної практики використовувати існуючі медичні інформаційні ресурси, їх функції та дані без спеціального обладнання, спеціальних програмних засобів та знань.

Повсеместное присутствие компьютеров в обществе, потребность в технологиях для выполнения нормативных требований приводит к обязательному использованию информационных систем во всех учреждениях здравоохранения.

Достойное место среди существующих медицинских информационных систем занимают системы поддержки принятия решений (Clinical Decision Support System, CDSS).

На сегодняшний день информационные системы поддержки принятия решений представляют собой, как правило, изолированные программы, рассчитанные на применение в рамках отдельно взятого медицинского учреждения и ориентированные на обеспечение частных функций и задач. Отсутствие единого подхода при их развитии в процессе эксплуатации привело к возникновению серьезных проблем. В результате, информационные ресурсы, методы работы с ними, программные средства, созданные в одном научном коллективе, редко становятся достоянием широких заинтересованных кругов. Это приводит к неоправданному дублированию, как при проведении научных исследований, так и при финансировании дорогостоящих работ (разработка программного обеспечения и др.).

Важным шагом на пути преодоления отмеченных недостатков являются интеграция и коллективное использование разнородных информационных ресурсов. Особое значение эти процессы имеют при разработке новых информационных технологий и систем поддержки принятия решений врача общей практики.

Эффективное решение врача общей практики основывается на высочайшем уровне концептуального понимания, действия по его практическому выполнению часто должны носить максимально оперативный характер. Кроме того, принимая решение, врач общей практики анализирует большое количество информации, так как для комплексной оценки состояния здоровья ему часто требуется взаимодей-

(c) Е. В. Высоцкая ствие со специализированными звеньями системы здравоохранения.

С целью использования уже разработанных программных продуктов для врачей-специалистов различных специализаций мы предлагаем использовать централизованную установку системы поддержки принятия решения врачом общей практики в «частном» облаке с подключением неограниченного количества врачей-консультантов, медицинских баз данных и АРМ врачей-специалистов.

Предлагается следующая типовая схема внедрения «Облачной системы» поддержки принятия решений врача общей практики:

- при возникновении необходимости обслуживать много (50 и выше) АРМ врачей создавать один общий центр обработки данных (ЦОД) для работы «частного облака системы».

- на каждом рабочем месте врача создавать свою инфраструктуру (сети, ПК, принтеры), организовать выделенный (желательно - оптический) канал связи от врача к ЦОДу, а также предусмотреть резервный канал связи.

- В ЦОДе установить централизованный стек серверного оборудования и систему хранения данных. В них специальными средствами для каждого АРМа создавать свои «виртуальные» разделы (серверы) для обслуживания серверной части системы поддержки принятия решений семейного врача. В каждом таком разделе будет функционировать своя «виртуальная» система, обсуживающая только данного врача. За счет сепарации отдельных инсталляций системы достигается надежная защита медицинских данных от несанкционированного доступа других лиц.

Также предполагается функционирование выделенного виртуального сервера для обслуживания общего информационного ресурса (ОИР). Т.к. физически сервер ОИР располагается в ЦОДе, то обмен данными между врачом и ОИР осуществляется максимально быстро и надежно. Также скорость 
обмена данными между врачами высока за счет консолидации виртуальных серверов АРМ врачей в одном ЦОДе, а в силу того что передача данных между врачами по открытым каналам фактически отсутствует, защита от несанкционированного перехвата данных существенно упрощается.

Как средство обеспечения совместимости различных медицинских информационных ресурсов предполагается использование медицинских технологических стандартов - моделей медицинских услуг, норм и нормативов, систем классификации и кодирования медицинской информации.

Так как в разрабатываемой системе предполагается использовать уже существующие информационные ресурсы, часть из которых создавалась и развивалась как автономные системы, для использования их функций и данных в разнообразных аспектах при принятии решений семейным врачом, необходимо применение информационного шлюза, который позволит создать высокопроизводительную специализированную сеть, объединяющую системы хранения и обработки данных из уже существующих информационных ресурсов. Ее внедрение позволит реализовать концепцию «централизованное хранение/ распределенная обработка данных», которая имеет ряд существенных практических преимуществ. Использование шлюзов позволит приложениям оперировать базами данных в «чужом» формате так, как будто это собственные базы данных. Цель шлюза организация доступа к унаследованным базам данных. Информационный шлюз служит для решения задач согласования форматов баз данных при переходе к какой-либо одной системе управления базами данных.

Выводы. Использование предлагаемого подхода к разработке информационной системы поддержки принятия решений семейного врача позволит осуществить взаимодействие различных медицинских информационных систем, даст возможность компьютерным сетям, устройствам, приложениям или компонентам обмениваться информацией между собой и использовать эту информацию. Врач общей практики сможет использовать информацию из большого числа источников, вне зависимости от того, на каких устройствах и при помощи каких программных средств эта информация создана, без специального оборудования, специальных программных средств и специальных знаний о настройках таких систем. 